\title{
The Microstructure of the Irish Stock Market
}

\author{
Patricia Chelley-Steeley \\ University of Aston, U.K. \\ Brian Lucey \\ Trinity College Dublin, Ireland
}

This is the first paper to examine the microstructure of the Irish Stock Market empirically and is motivated by the adoption, on June 7th of Xetra the modern pan European auction trading system. Prior to this the exchange utilized an antiquated floor based system. This change was an important event for the market as a rich literature exists to suggest that the trading system exerts a strong influence over the behavior of security returns. We apply the ICSS algorithm of Inclan and Tiao (1994) to discover whether the change to the trading system caused a shift in unconditional volatility at the time Xetra was introduced. Because the trading mechanism can influence volatility in a number of ways we also estimate the partial adjustment coefficients of the Amihud and Mendelson (1987) model prior and subsequent to the introduction of Xetra. Although we find no evidence of volatility changes associated with the introduction of Xetra we do find evidence of an increase in the speed of adjustment (JEL: G15).

Keywords: trading systems, adjustment speed, cross listing, microstructure.

\section{Introduction}

This paper examines the behavior of a group of securities cross-listed on the Dublin and London stock exchanges. These securities are particularly interesting because between 1973 and 1995 Irish companies were able to obtain a listing on the London market and trade alongside UK stocks. By 1995 when the two stock exchanges formally separated a large number of Irish stocks were cross listed on both the London and Dublin exchanges giving traders a choice of where to transact.

(Multinational Finance Journal, 2008, vol. 12, no. 3/4, pp. 279-311)

Quarterly publication of the Multinational Finance Society, a nonprofit corporation.

(C) Global Business Publications. All rights reserved.

DOI: $10.17578 / 12-3 / 4-6$ 
Despite the close regulatory ties between Dublin and London the two exchanges adopted very different trading systems. From 1986 the London Stock Exchange utilized an electronic quote driven system called SEAQ but the system in Dublin was floor based and nonautomated. However, on June 7, 2000 a major overhaul of the Irish market took place which saw the introduction of an electronic order driven system called Xetra. Motivated by the numerous studies that have suggested that the trading mechanism can influence the behavior of stock returns (e.g., Cohen, Maier, Schwartz and Whitcomb [1978], Black [1986], Amihud and Mendelson [1987], Handa and Schwartz [1995], Huang and Stoll [1996], Ozenbas, Schwartz and Wood [2002] or Pagano and Schwartz [2003]) we examine the effects that the introduction of Xetra had on the returns of both Dublin and London cross listed stocks.

In the first instance, we apply the ICSS algorithm of Inclan and Tiao (1995), which tests for a change to the unconditional volatility of a series. We apply this test to the stock returns of those securities cross listed on both the Dublin and the London markets. We then investigate whether there is any evidence of a widespread change in variance associated with the introduction of Xetra. We find that the introduction of Xetra appeared to have no consistent impact on return volatility.

The partial adjustment model of Amihud and Mendelson (1987) shows that volatility is determined by a range of factors which can have an offsetting influence on volatility. We extend our analysis and consider whether the introduction of Xetra changed the speed of price discovery in the post Xetra period. We find that the introduction of Xetra caused both London and Irish prices to adjust to their fundamental values more quickly, providing a higher degree of operational efficiency in both markets.

The remainder of this paper is set out as follows. Section II provides a literature review. Section III describes the microstructure of the Dublin and London market. Section IV describes the data and provides some summary statistics. Section V uses GARCH to measure variance changes in the post Xetra period. Section VI describes the ICSS algorithm and the results from using this test. Section VII describes the estimation of the partial adjustment model and provides results. Section VIII provides a summary and conclusion to the paper. 


\section{Literature Review}

Intense competition between European stock exchanges has induced wide ranging changes to the mircrostructure of these markets. Across Europe there have been a wave of innovations that have modified trading mechanisms, increased the diversity of trading systems and encouraged the development of pan European trading platforms (many of these developments are discussed in detail by Pagano [1997]). A consequence of these evolutions is that attention has re-focused on the impact that changes to market structure could have on the behavior of returns, e.g., Gemmill (2001), Venkataraman (2001), Pagano and Schwartz (2003) and Chelley-Steleey (2005).

Considering the impact of the trading mechanism on the behavior of stock returns is not new. Pioneering work by Amihud and Mendelson (1980) and (1982) demonstrates how the actions of a dealer, may reduce the noise associated with the price setting process. Market makers contribute to lower volatility, by changing inventory in response to temporary imbalances in the order flow. These actions smooth prices leading to lower volatility.

Ozenbas, Schwartz and Wood (2002) have argued that market structure exerts an important influence over noise generated in the price setting process. They argue that uncertainty about the intrinsic value, because of information or trading frictions, leads to greater errors in the analysis and interpretation of information. Biais (1993) analyzes the performance of fragmented and centralized markets, with different levels of transparency. In the centralized market dealers compete with each other to attract the order flow, and observe the quotes and transactions of competitors. In the fragmented market, transactions arise as a result of bilateral negotiations, and market makers cannot observe their competitors' quotes or the intensity of their desires to trade. The model shows that although the bid-ask spread is the same in both types of markets, the volatility of the spread in the centralized market is higher. More recently Handa and Schwartz (1996) have shown that in a limit order trading system, when there is a shortage of orders, there is a rise in return volatility.

One way of comparing two trading mechanisms empirically is to use the approach suggested by Amihud and Mendelson (1987), who studied the volatility of returns from different trading mechanisms. Because the NYSE opens with a call auction but trades as a specialist dealer market thereafter, open to open returns reflect the influence of the opening 
auction while close to close returns reflect the influence of the specialist dealer market. Comparisons of opening and closing prices led Amihud and Mendelson (1987) and Stoll and Whaley (1990) to conclude that open to open returns are on average $20 \%$ more volatile than close to close returns. This research has encouraged the belief that call auctions have been a more noisy trading mechanism than continuous dealer markets, inducing more volatility. However, the advantages of the call auction are discovered by Amihud and Mendelson (1991) who study the Japanese market and find that the intraday call auction is the trading mechanism associated with the lowest level of volatility. Their findings support Madhaven (1992) who argues that call auctions are the most efficient price discovery mechanism of all. More recently, Pagano and Schwartz (2003) found that the introduction of a closing call auction in Paris improved the quality of both opening and closing prices.

A number of recent studies have investigated the effect that changing the trading mechanism has had on the volatility of returns. As a result, the problems of separating out the influence of the open from market structure have been circumvented. Gemmill (2001) and Chelley-Steeley (2004) both examine the volatility of the London Stock Exchange in the aftermath of the introduction of a new electronic order driven system (SETS). Both papers find that volatility is considerably enhanced after SETS is introduced. However, when Ronen (1998) examines a change to the opening trading mechanism at the Tel-Aviv Stock Exchange, he finds that return volatility is not influenced by the trading mechanism. This finding is also supported in experimental work by Theissen (2000) who examines the price setting process of auction and dealer markets.

Although there has been a global trend away from floor based trading the benefits of automation are not clear cut. Benveniste, Marcus and Wilhelm (1992) argue that professional relationships evolve on the floor of an exchange. Repeated interactions between traders leads to information sharing ensuring that information asymmetries are reduced resulting in higher liquidity. These benefits however have to be offset against the lower trading costs associated with automated systems, see Domowitz and Steil (1999) and Venkataraman (2002).

A model able to capture the multilateral influences of the trading mechanism is the following partial adjustment model with noise introduced by Amihud and Mendelson (1987):

$$
P_{t}-P_{t-1}=g\left(V_{t}-P_{t-1}\right)+u_{t}
$$

where $P_{t}$ is the logarithm of observed prices and $V_{t}$ is the logarithm of 
the fundamental price, $0<g<2, E\left(u_{t}\right)=0$ and $\operatorname{var}\left(u_{t}\right)=\sigma^{2}$. The $\left\{u_{t}\right\}$ are a white noise sequence of zero mean pricing errors which are i.i.d. with a finite variance denoted as $\sigma^{2}$. The $u_{t}$ reflect the influence of noise, which pushes observed prices away from their intrinsic value. As noise increases, $\sigma^{2}$ becomes progressively larger causing observed returns to become more volatile. Thus fragmentation, the size of bid ask spreads, the price cushioning effect of a dealer, and other effects of the trading mechanism can all influence the magnitude of $\sigma^{2}$.

The coefficient $g$ is a partial adjustment parameter that captures the speed with which observed stock prices adjust to their fundamental value. When $0<g<1$, the current transaction price gradually adjusts towards the fundamental value of the stock, if $g=0$, then transaction prices do not adjust to changes in value. When $g=1$, there is full but noisy, price adjustment. When $g>1$ observed prices over-react to new information.

In this model intrinsic prices, $V_{t}$, follow a random walk with drift as shown below:

$$
V_{t}=m+V_{t-1}+e_{t}
$$

where $m$ is the positive drift which reflects the magnitude of the daily expected return. The $\left\{e_{t}\right\}$ are a series of i.i.d. random variables, independent of $u_{t}$, with a zero mean and finite variance, which can be denoted as $v^{2}$.

Amihud and Mendelson show that the variance of observed returns is given by:

$$
v a r=\frac{g}{2-g} v^{2}+\frac{2}{2-g} \sigma^{2}
$$

where $[g /(2-g)] v^{2}$ represents the contribution that the variation in the intrinsic price $v^{2}$ makes to the observed variance, while $[2 /(2-g)] \sigma^{2}$ captures the influence that noise has on the observed variance. Thus the variance of observed returns is positively related to three factors, the variance of intrinsic prices, the amount of noise, and the magnitude of the partial adjustment coefficient. If $0<g<1$ then the influence of the partial adjustment coefficient will dampen down the influence that noise has on the observed variance, because the partial adjustment process has a smoothing influence on observed returns. But, if $g$ is greater than one 
(so that the market is over-reacting to new information), the price adjustment effect will be positive increasing the variance of observed returns.

This model shows how the change from one trading mechanism to another can influence the volatility of stock returns. A new trading mechanism that reduces trading costs, the volatility of the spread or errors made by analysts in the interpretation of new information may reduce volatility caused by noise. However, this would be offset if the new trading mechanism increased the speed of price discovery.

\section{The Microstructure of the Irish and London Stock Market}

The Irish Stock Exchange was established in 1793 and throughout its history it has had close links with the London Stock Exchange. In 1973 the Irish Exchange was admitted to the "International Stock Exchange of Great Britain and the Republic of Ireland" creating a union between the two exchanges. During the 1990's the two markets gradually separated. The Companies Act of 1990 gave the Irish Exchange the powers of self-regulation and the Stock Exchange Act of 1995 formally separated the two exchanges. Despite the regulatory alliance between the two exchanges the Dublin and London exchanges utilized very different trading systems.

Prior to the introduction of Xetra the Dublin Exchange held two floor based trading sessions. These were held 9:30-10:30 am and 2:15-3:15 pm each weekday. During each of these sessions member firms were required to employ a representative on the floor. Official trading required members to match buy and sell orders prior to execution. Normal trades matched orders against those from other member firms while "put-throughs" matched buy and sell orders from different clients at the same price. Traders were not allowed to act as a market maker and hold inventory on their own account. However, when dealing for a client without a counter party they could hold up to 2,000 euro of inventory when no matching trade existed. ${ }^{1}$ This ensured that small traders always had immediacy but exposed those wishing to trade large volumes to counter party risk.

When a deal was struck the price was noted on a chalkboard. Filled

1. Prior to the introduction of the euro in January 2000 traders were allowed to hold 2,000 Irish Punt in inventory. 
orders were communicated back to the member firms by a "blower" telephone system which informed all firms of the transactions undertaken. Deals made after the close of an official session could only be executed at the beginning of the next trading session. It was a widely held belief that the matching system and the small number of member firms operating on the Dublin market created an impediment to competition.

In 1986, the London Stock Exchange launched SEAQ, a dealer trading system consisting of competing market makers with dual capacity. For each stock trading on SEAQ, the system provides an electronic display of bid and ask prices quoted by the market makers registered for that equity. The most competitive prices are highlighted in yellow and are known as the yellow strip or touch. Registered market makers are required to provide firm quotes for trades up to Normal Market Size (NMS) during the mandatory quote period (8:00 am-4:30 $\mathrm{pm}){ }^{2}$ SEAQ market makers are not allowed to display prices on competing display systems that are better than those displayed on SEAQ. From 1986 onwards Irish stocks listed in London were traded on SEAQ. Unlike the Dublin market pre-Xetra London could offer continuous trading throughout the day. This provided the London market with an important strategic advantage. New information arriving during a Dublin trading halt could be reflected in London prices immediately but would only be reflected in Dublin prices once a new trading session began. Dublin prices were therefore likely to be more stale than London prices.

SEAQ is an example of a fragmented market since over half of all trades are the consequence of telephone negotiation between market maker and customer, e.g., Board and Sutcliffe (1995) and (2000). However, Dublin is also a fragmented market as a significant amount of trading takes place in London away from the domestic market. On SEAQ large trades can be reported with a delay reducing the degree of post trade transparency. Although, prior to Xetra trades in Dublin were reported immediately the dissemination of this information was undertaken by hand and subsequently relayed through a telephone system reducing the speed of information transmission. Since SEAQ market makers buy and sell on their own account, unlike the pre-Xetra Dublin market, London provides immediacy even for large trades.

On June 7, 2000 the Irish stock exchange adopted Xetra as its

2. NMS approximately reflects the size of the median transaction. 
official trading system, heralding a major overhaul to the microstructure of the Dublin market. The modernization of the Irish exchange was made against a background of heightened competition between London and Dublin which had increasingly seen trades in Irish stocks migrate to London.

Unlike the floor based system, Xetra is a fully electronic trading system able to offer continuous trading throughout the day; active trading takes place between 8:00 am and 4:30 pm. Trading is separated into three phases, pre-trading, main trading and post trading. Pre-trading takes place between 6:30 am and 7:50 am when traders can add, modify or delete orders. During this time the order book is closed and no information from the order book is disseminated to the market. The main trading phase is divided into two types of trading; auctions and continuous trading. Each auction has three parts. The first is a call stage when market participants are able to enter orders and quotes as well as modify or delete existing orders. During this phase the order book is closed, although information on the state of the order book is provided to the market along with indicative auction prices. ${ }^{3}$ The call phase is followed by price determination, which identifies the auction price. The auction price is chosen to allow the highest order volume to be executed, at a single market clearing price. If an auction price can not be determined no orders are executed. When this happens, the best bid and ask limits are displayed. If there is a surplus of orders at this price, an order balancing phase takes place. This allows those orders unable to be executed at the auction price to become available to the market. During the order book balancing phase orders are executed at the determined auction price. ${ }^{4}$ The opening auction takes place between 7:50 am and 8:00 am and closing auction takes place between 4:28 am and 4:30 pm. Intraday auctions may also take place.

Continuous trading takes place between 8:00 am and 4:28 pm, when the order book is fully open, displaying limit orders with accumulated volumes, as well as the number of orders on the book at each limit price. Orders are executed in order of price then time priority. Between 4:30 $\mathrm{pm}$ and 5:15 pm a post trading phase takes place where orders may be added, deleted or modified; these will be executed the following day.

To safeguard price continuity, a trading interuption occurs if a

3. If an indicative price can not be displayed then the best bid-ask prices are displayed.

4. Orders can not be changed or added at this stage. 
security price moves outside specified ranges (known as dynamic or static price ranges). If a volatility interuption takes place during a call auction the call phase is extended until the potential execution price lies within the allowed range. ${ }^{5}$ During continuous trading, if the executable price lies outside the range allowed continuous trading is interrupted by a call auction.

To protect the positions of those trading large volumes, iceberg orders may be placed. These allow an order to be partially hidden. Each iceberg has a peak (the visible part of the order) and an overall volume (the full order to be executed). In continuous trading, as soon as the peak is completely executed, and if a hidden volume still exists, a new peak is entered into the book with a new time stamp. Iceberg orders participate with their overall volumes in call auctions. Unlike other orders icebergs are only valid for one trading day. ${ }^{6}$ All trades on Xetra are reported immediately.

Because the order book is highly visible on Xetra, pre-trade transparency is considerably higher on Xetra when compared to the floor based system. The almost instantaneous reporting of all trades ensures that Xetra also provides higher levels of post-trade transparency. These changes in transparency are likely to give rise to more efficient price discovery in the Dublin market and possibly in London.

\section{Data and Summary Statistics}

We examine a group of Irish stocks that were transferred to the Xetra trading mechanism on June 7, 2000. To be included in the sample each stock must trade between June 6, 1998 and June 5, 2003 and be cross listed in London throughout the sample period. In all this provides us with sixteen companies, listed in appendix 1. Each stock was traded on the Irish floor based market between June 6, 1998 and June 5, 2000 but traded on the Xetra auction system between June 6, 2000 and June 6, 2003. Daily closing prices were obtained from Datastream. We focus on closing prices rather than intraday prices for two reasons. Because the Irish market is thinly traded high frequency prices may provide distorted

5. If the price continues to remain outside the dynamic and static range a wider price range is imposed and price determination is allowed to take place.

6. Minimum peak sizes and minimum overall volumes are specified foe ISE Xetra. 


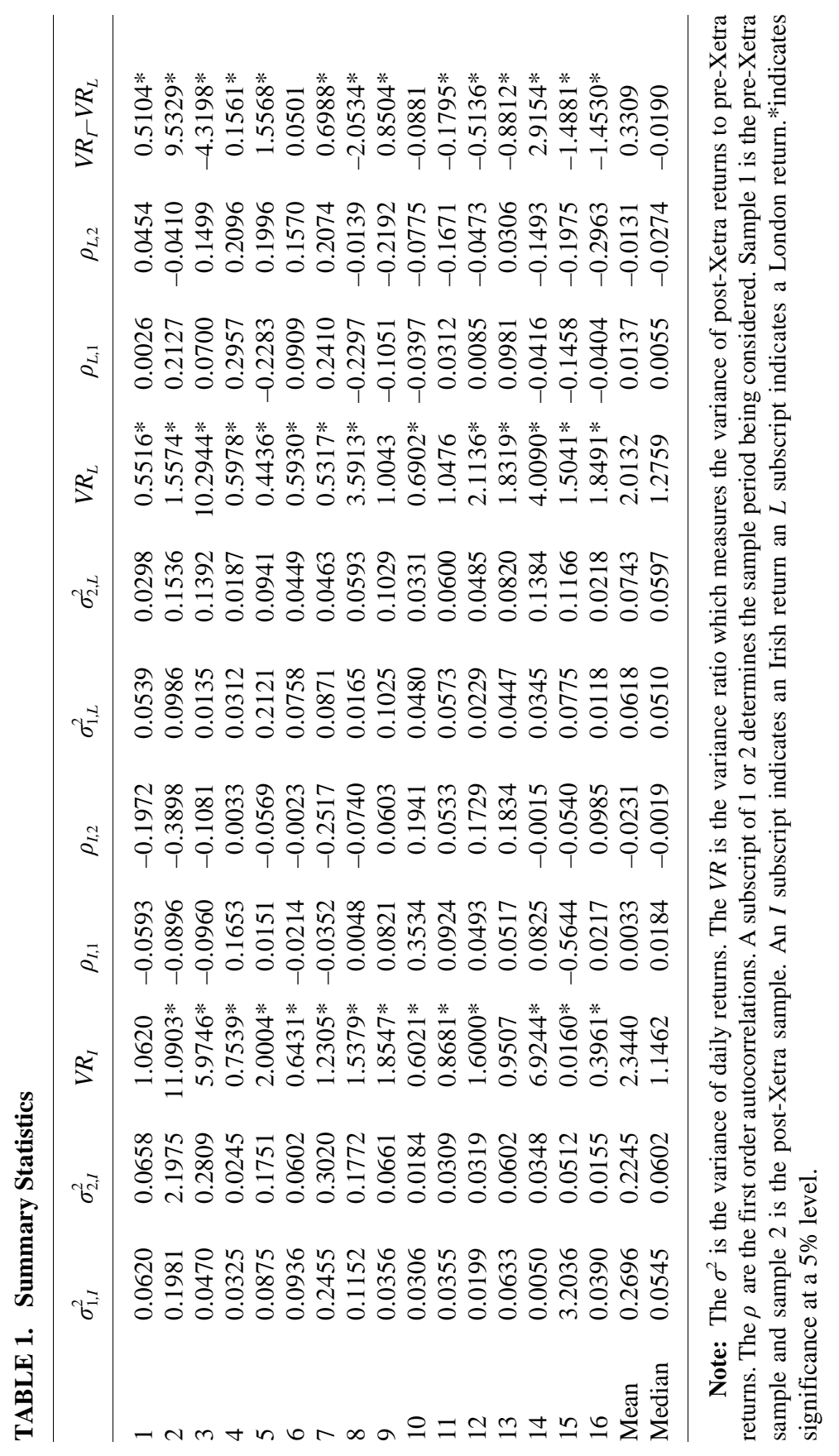


results. Second, prior to the introduction of Xetra the Irish Exchange did not archive intraday information.

Table 1 contains the variance and first order serial correlation of both Irish and London returns for both sub-periods. Table 1 also presents a variance ratio statistic, which is the ratio of the variance of post-Xetra returns divided by the variance of pre-Xetra returns. A variance ratio greater than one would indicate that stock returns are higher after Xetra was introduced. The variance ratios for Irish returns suggest a tendency for volatility to be higher post-Xetra. The mean variance ratio is 2.344 showing that average stock return volatility increased by $134 \%$ (eight Irish securities have a variance ratio statistically greater than one). For London returns the mean variance ratio statistic is 2.01 (eight securities have variance ratios statistically greater than one).

We also apply a Levene test, a nonparametric test able to detect a change in variance across two samples. The test statistic is

where

$$
W=\frac{(N-k) \sum_{s=1}^{k} N_{s}\left(\bar{Z}_{s}-\bar{Z}\right)^{2}}{(k-1) \sum_{s=1}^{k} \sum_{t=1}^{N}\left(\bar{Z}_{s, t}-\bar{Z}_{s}\right)^{2}},
$$

$$
\bar{Z}=\sum_{s=1}^{k} \sum_{t=1}^{N_{s}} Z_{s, t} / \sum_{s=1}^{k} k N_{s}
$$

and $k$ is the number of samples.

In this context $k=2$ representing the period prior and subsequent to the introduction of Xetra. $Z_{s t}=\left|Y_{s t}-Y^{\prime}\right|$ where $Y^{\prime}$ is the median return of subgroup $I$ and

$$
\bar{Z}_{s}=\sum_{t=1}^{N_{s}} Z_{s, t} / N_{s} .
$$

The Levene test rejects the hypothesis that the variances are homogeneous if $W>F_{(1-a, k-1, N-1)}$ where $F_{(\cdot)}$ is the critical value of the $F$ distribution with $k-1$ and $N-1$ degrees of freedom at a significance level of $a$. There are ten examples of a variance change to both London and Ireland returns. Of these six occur in both markets. This suggests that the variances of all securities are not constant across the two trading environments either in London or Dublin. 
TABLE 2. Results from the Levene Test

\begin{tabular}{lrlrl}
\hline Company & $W_{I}$ & $p$ & $W_{L}$ & $p$ \\
\hline 1 & 5.65 & $0.02^{*}$ & 0.08 & 0.78 \\
2 & 69.44 & $0.00^{*}$ & 0.29 & 0.59 \\
3 & 52.94 & $0.00^{*}$ & 27.61 & $0.00^{*}$ \\
4 & 0.27 & 0.60 & 0.38 & 0.54 \\
5 & 22.92 & $0.00^{*}$ & 11.47 & $0.00^{*}$ \\
6 & 0.34 & 0.56 & 0.68 & 0.97 \\
7 & 22.38 & $0.00^{*}$ & 0.77 & 0.38 \\
8 & 12.06 & $0.00^{*}$ & 2.30 & 0.13 \\
9 & 0.39 & 0.53 & 4.30 & $0.04^{*}$ \\
10 & 12.45 & $0.00^{*}$ & 7.29 & $0.01^{*}$ \\
11 & 2.56 & 0.11 & 4.33 & $0.04^{*}$ \\
12 & 5.08 & $0.02^{*}$ & 41.97 & $0.00^{*}$ \\
13 & 2.02 & 0.16 & 24.63 & $0.00^{*}$ \\
14 & 7.71 & $0.01^{*}$ & 33.34 & $0.00^{*}$ \\
15 & 51.34 & $0.00^{*}$ & 5.32 & $0.02^{*}$ \\
16 & 0.11 & 0.74 & 64.17 & $0.00^{*}$ \\
\hline
\end{tabular}

Note: The $W$ is the Levene statistic (see equation 4) and $p$ is its probability value. An $L$ subscript indicates that the test utilized London returns and an $I$ indicates Irish returns. *indicates significance at a $5 \%$ level.

\section{GARCH Estimation}

The variances presented in table 1 are useful summary statistics but may be biased because they assume homoscedasticity of returns. ${ }^{7}$ The Levene statistic, despite being a non-parametric statistic, it is unable to confirm whether the variance has risen or fallen in value.

We therefore enhance our comparisons of volatility by using the GARCH family of statistical processes to model the conditional mean and variance of security returns. In equation 5 returns are modeled as an $\operatorname{ARMA}(1,1)$ process which has been shown to be an appropriate specification for conditional mean returns, (e.g., Conrad, Kaul and Nimalendran [1991]; and Liu and Pan [1997]) with the addition of the market index $M_{j, t}$. This addition allows us to control for changes in volatility caused by market movements which are unrelated to the trading mechanism. For London returns the market control is the FT-All

7. The heteroscedastic nature of stock returns is discussed by Mandelbrot (1963), Fama (1965) and Bollerslev, Chou and Kroner (1992). 
share index and for the Irish market it is the ISEQ Index. That is,

$$
\begin{gathered}
R_{i, j, t}=\alpha_{i, j}+\varphi_{i j} R_{i, j, t-1}-\theta_{i, j} \xi_{i, j, t-1}+m_{i, j} M_{i, j}+\xi_{i, j, t}, \\
\text { for } j=1 \text { and } 2 \text { and } i=1,2,3, \ldots, 16,
\end{gathered}
$$

where $R_{i, j, t}$ are the returns for security $i$ in either the London market or the Irish market in time $t$. The $\xi_{i, j, t}$ is the unexpected return or shock and $\alpha_{i}, \varphi_{i}, \theta_{i}$ and $m_{i, j}$ are coefficients. The estimated GARCH model is the one suggested by Glosten, Jagannathan and Runkle (1993), which allows us to isolate the impact that negative stock returns have on volatility. This model is recommended by Engle and $\mathrm{Ng}$ (1993) as the parametric model most able to capture the asymmetries which may give rise to a leverage effect (negative relationship between stock price movement and volatility), e.g., Black (1976) and Christie (1982). That is, the conditional variance of returns is specified as:

$$
h_{i, j, t}=b_{0, i, j}+b_{i, j} \xi_{i, t-1}^{2}+c_{i} h_{i, j, t}+d_{i, j} D_{1 i, j, t-1}+\delta_{i, j} D_{2}
$$

where $\xi_{i, t-1}^{2}$ is past volatility shock, appears twice; on its own, and with a multiplicative indicator dummy variable. This variable takes the value of unity if the past return was negative and a value of zero otherwise. Thus, the coefficient $\delta_{i, j}$ measures whether the sign of the return influences the conditional variance. If the coefficient is positive, it indicates that a negative shock will have a greater impact on future volatility than a positive shock, ie a leverage effect exists. $D_{2}$ is a dummy which takes on a value of zero pre-Xetra but takes a value of unity post-Xetra. Thus if $d_{i, j}$ is positive (negative) returns are more (less) volatile post-Xetra.

The results from the estimation of this model are included in table 7 for Irish returns and table 8 for London returns. Almost all $b_{i, j}$ and $c_{i, j}$ coefficients are significant and many of the securities in both Dublin and London are characterized by leverage effects. The value of $\delta_{i, j}$ is significant and positive for seven Dublin securities and is significant and negative for nine securities. A similar lack of consensus characterizes London returns. Seven of the $\delta_{i, j}$ coefficients are negative and nine are positive. This suggests that the influence of the trading mechanism may have been asymmetric across the different securities. This would be possible if the trading mechanism influenced both the amount of noise present and the partial adjustment process in the model 
outlined in section 2 .

Examining volatility across two sample periods alone may be problematic as volatility in the second sub-period may change for reasons unrelated to the trading mechanism. To overcome this problem we apply the ICSS algorithm of Inclan and Tiao (1994) and examine whether there is a widespread change to volatility at the time Xetra was introduced.

\section{Detecting Variance Shifts}

To estimate the number of changes in variance and the point at which each variance shift occurs Inclan and Tiao (1994) suggest a three step algorithm, applied successfully in Aggarwal, Inclan and Leal (1999). In the first instance, using the full data set the maximum absolute value of the $D_{k}$ series is calculated as:

$$
D_{k}=\frac{C_{k}}{C_{T}}-\frac{k}{N} \text { for } k=1,2, \ldots, T,
$$

where $C_{k}$ and $C_{T}$ are the mean centred cumulative sum of squares calculated from the start of the series to the $k$ th point in time (in all there are $T$ observations in each sample). If there are no variance changes over the sample period then the series $D_{k}$ oscillates around zero but drifts up or down from zero when a variance shift occurs. If max $\left|D_{k}\right|$ $\sqrt{ }(k / 2)$ is greater than the critical value $(1.358$ at $95 \%$ level of confidence) then a possible variance change point has been found.

Once a possible change point cpi has been identified after $\mathrm{m}$ observations the data should be partitioned into two groups spanning $\left(t_{1} \ldots t_{m-1}\right):\left(t_{m+1} \ldots T\right)$. The max $\left|D_{k}\right| V(k / 2)$ statistic is then calculated for each of the two new samples. In each of these two samples an additional change point could potentially be identified. This would require a further sub-division of the data, until all the data has been examined in intervals $t_{1}$ to each change point, until $T$ is reached and no further change points can be found.

In the third step all $N$ estimated change points should be recorded in order $c_{p 1}, c_{p 2}, \ldots, c_{p N}$. Assuming the two extreme values are $c_{p 0}$ where $t=0$ and $c_{p N+1}$ where $t=T$. Each possible change point should be re-checked by calculating $\left|D_{k}\right| \sqrt{ }(k / 2)$ for data observations spanning alternate change points $\left(c_{p i}: c_{p i+2}\right.$ until the change points $\left(c_{p N-2}: c_{p N}\right)$ are reached. If max 


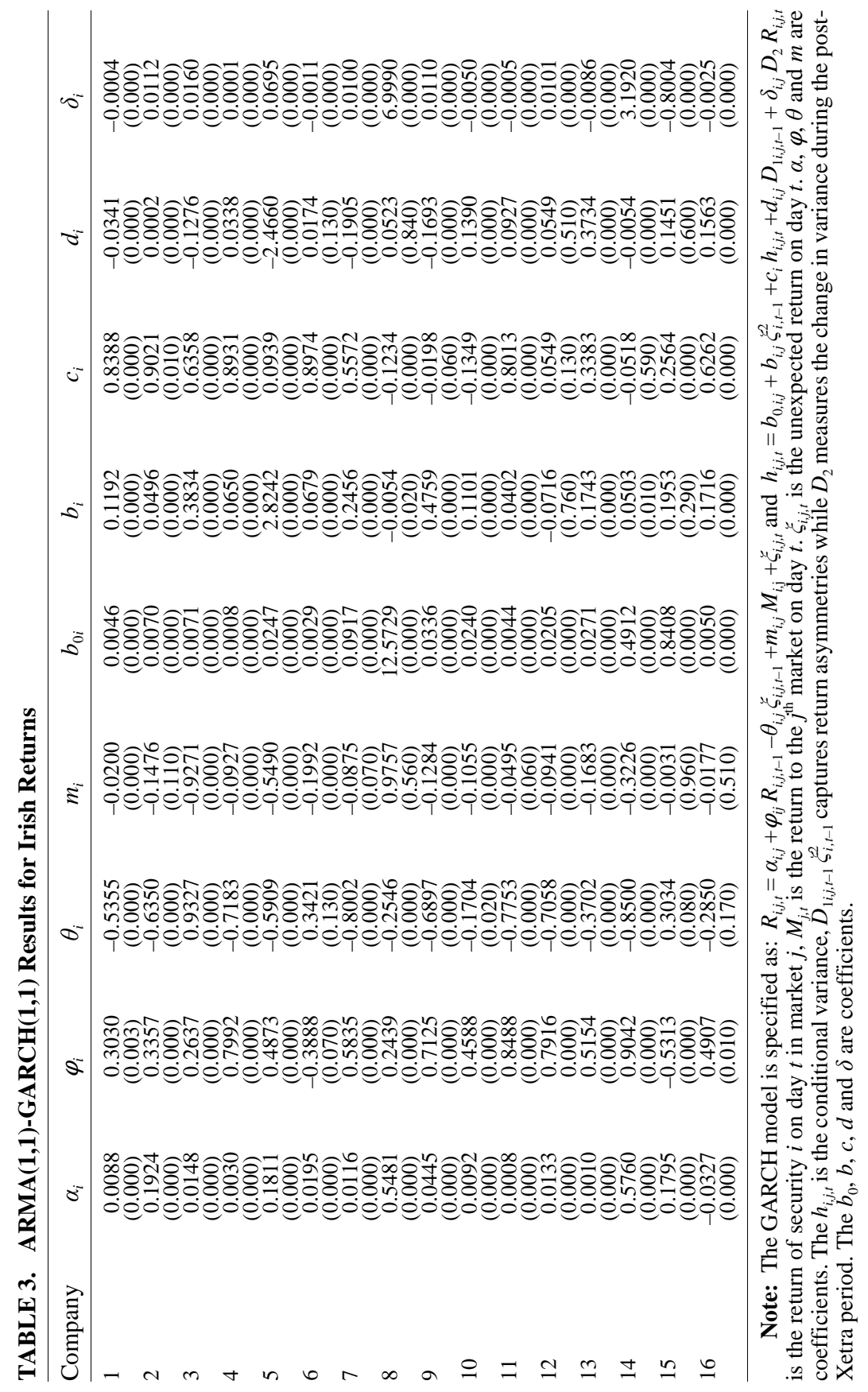




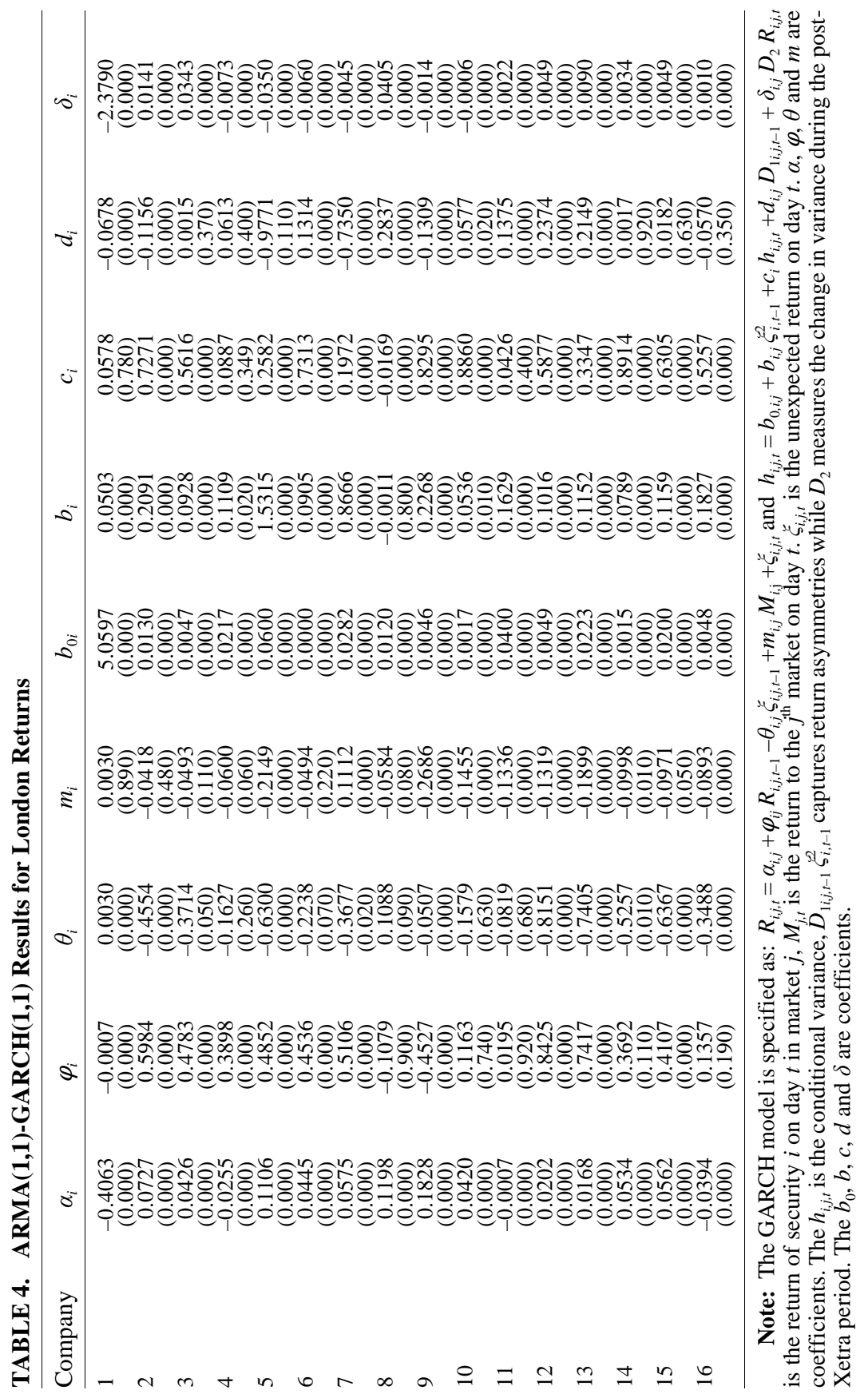


$\left|D_{k}\right| \sqrt{ }(k / 2)$ no longer reaches the critical value the possible change point should be eliminated. This step should be repeated until the number of change points found in each pass of the data does not change and the change points found are "close" to those of the previous pass. ${ }^{8}$

Asymptotic critical values for the ICSS algorithm have been determined assuming that returns are uncorrelated. Since table 1 shows evidence of serial correlation, prior to the application of the ICSS algorithm we apply an $\operatorname{ARMA}(1,1)$ filter to each of the stock return series.

Table 3 contains all the variance changes for Dublin returns and shows that the unconditional variance of each stock return series is non-stationary. Most stocks have over ten variance changes during the sample period. Those shifts in variance which occur within one week prior and one month subsequent to the introduction of Xetra are highlighted in bold. Only four variance shifts coincide with the introduction of Xetra. Table 4 contains information on the variance of each stationary variance interval and the percentage increase or decrease each interval represents. This table shows that of the variance changes that coincide with the introduction of Xetra two represent an increase in variance and two represent a decrease in variance.

The dates of the variance shifts are shown in table 5 for London returns. Four of the variance shifts coincide with the introduction of Xetra. Table 6 presents the variances of each interval and shows that three of these variance shifts are variance decreases and one is a variance increase. The results suggest that there is no widespread change to volatility at the time Xetra was introduced. This contrasts with Gemmill (1991) and Chelley-Steeley (2004) who discover volatility increased when SETS is introduced in London. A possible explanation for this is that unlike SETS, prior to its introduction Xetra had been used in Frankfurt for several years and was not therefore a new trading system and the market may have reacted to its introduction differently. In the remainder of this paper we explore the possibility that changes to volatility may be unobservable because the price discovery process and noise caused by the trading system may have caused offsetting changes to volatility.

8. $n$ is the number of observations used to calculate *. Under the null hypothesis that the variance is homogeneous over the entire series, asymptotically * behaves as a Brownian bridge when underlying returns are i.i.d.. Throughout we consider a confidence level of $95 \%$ which has a critical value of 1.358 and prior to the estimation of * test whether security returns are uncorrelated. (Note!!! define *) 


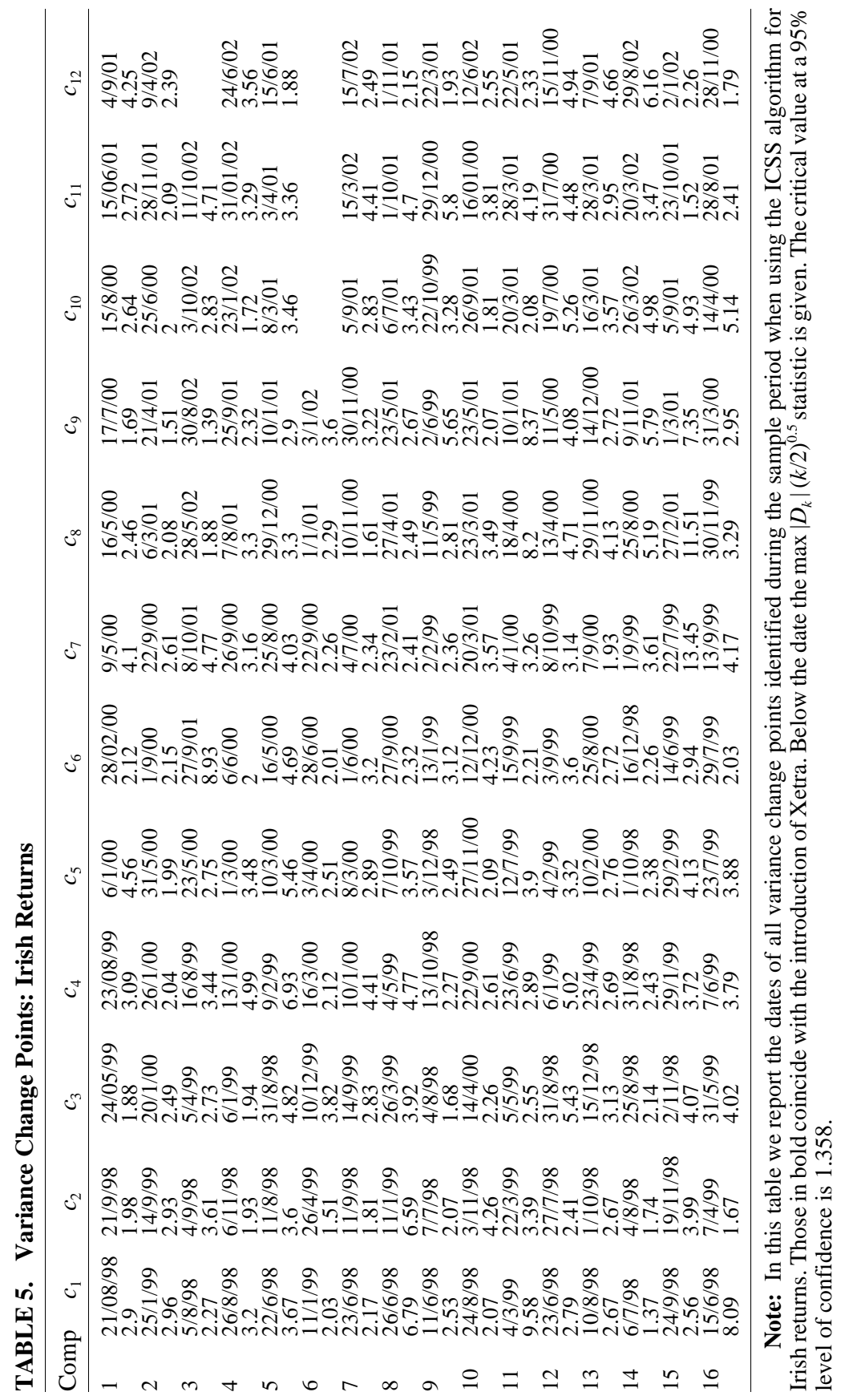




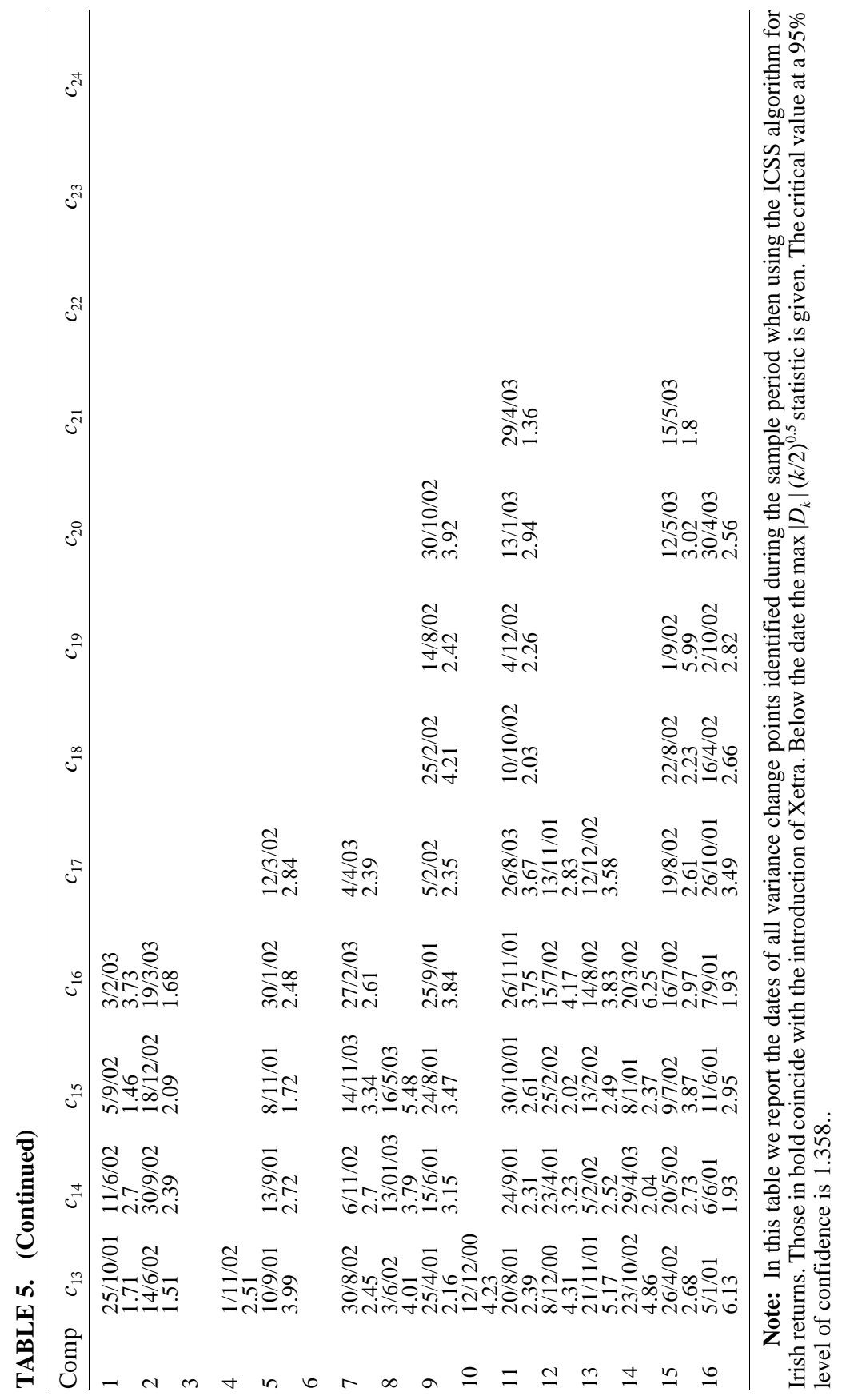




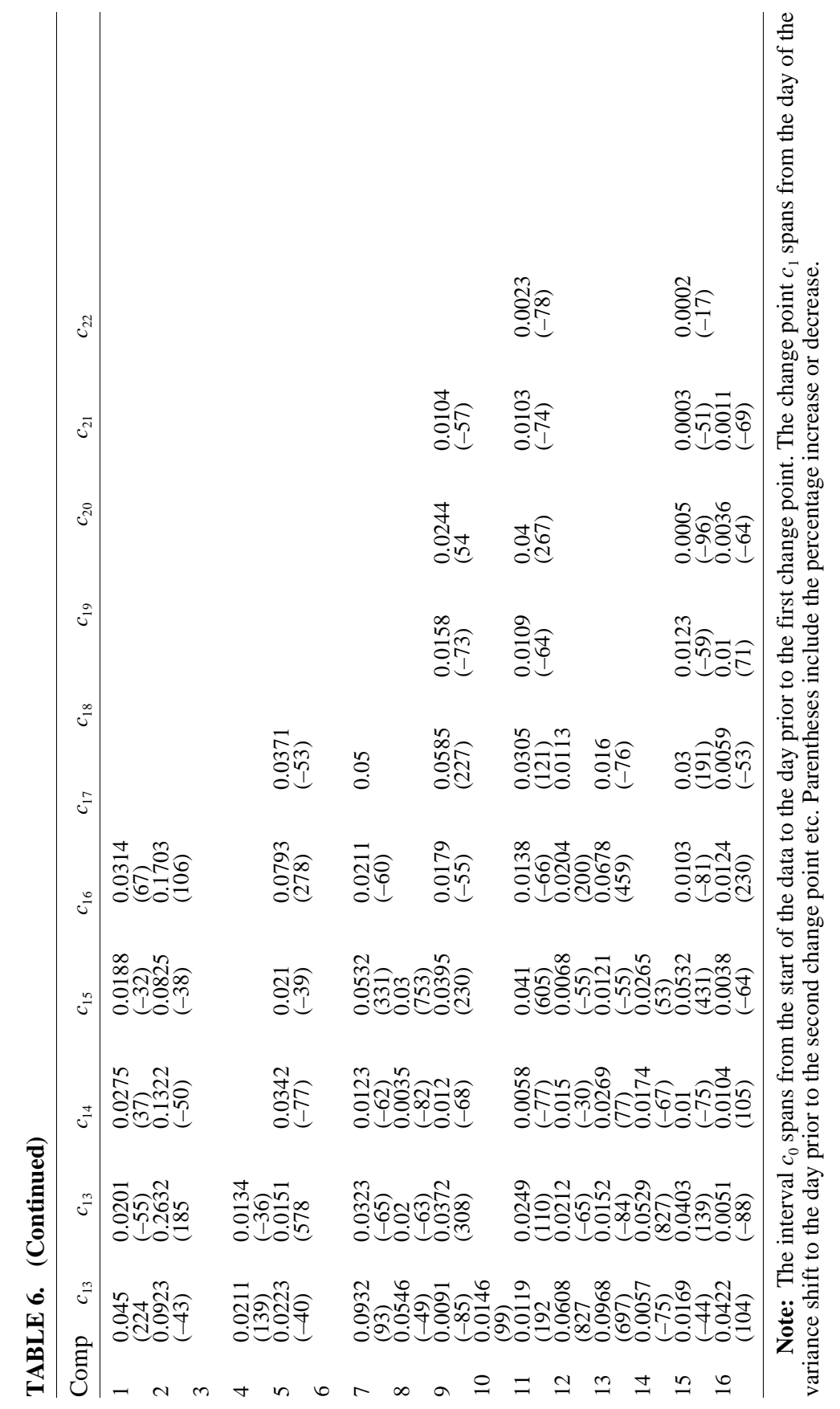




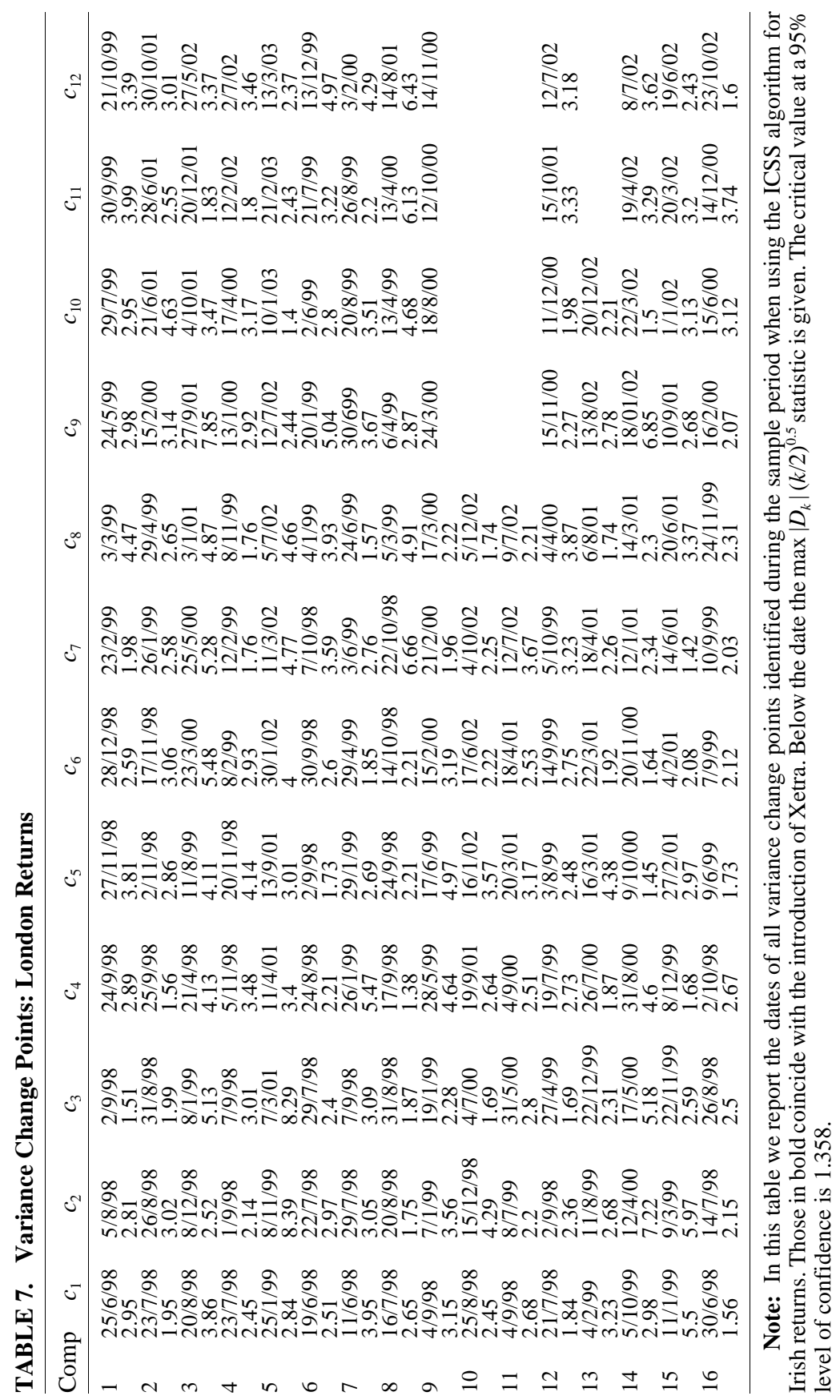




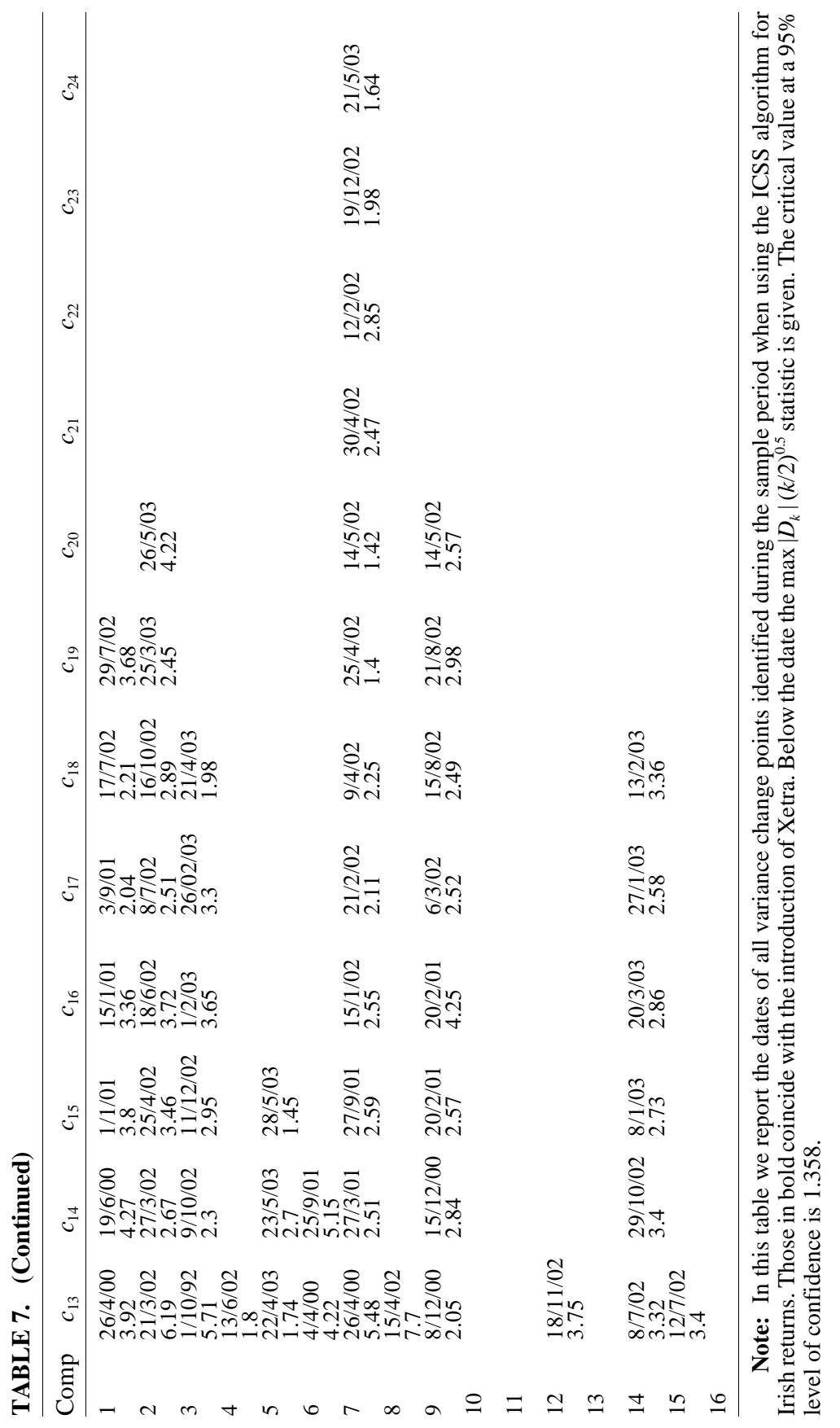




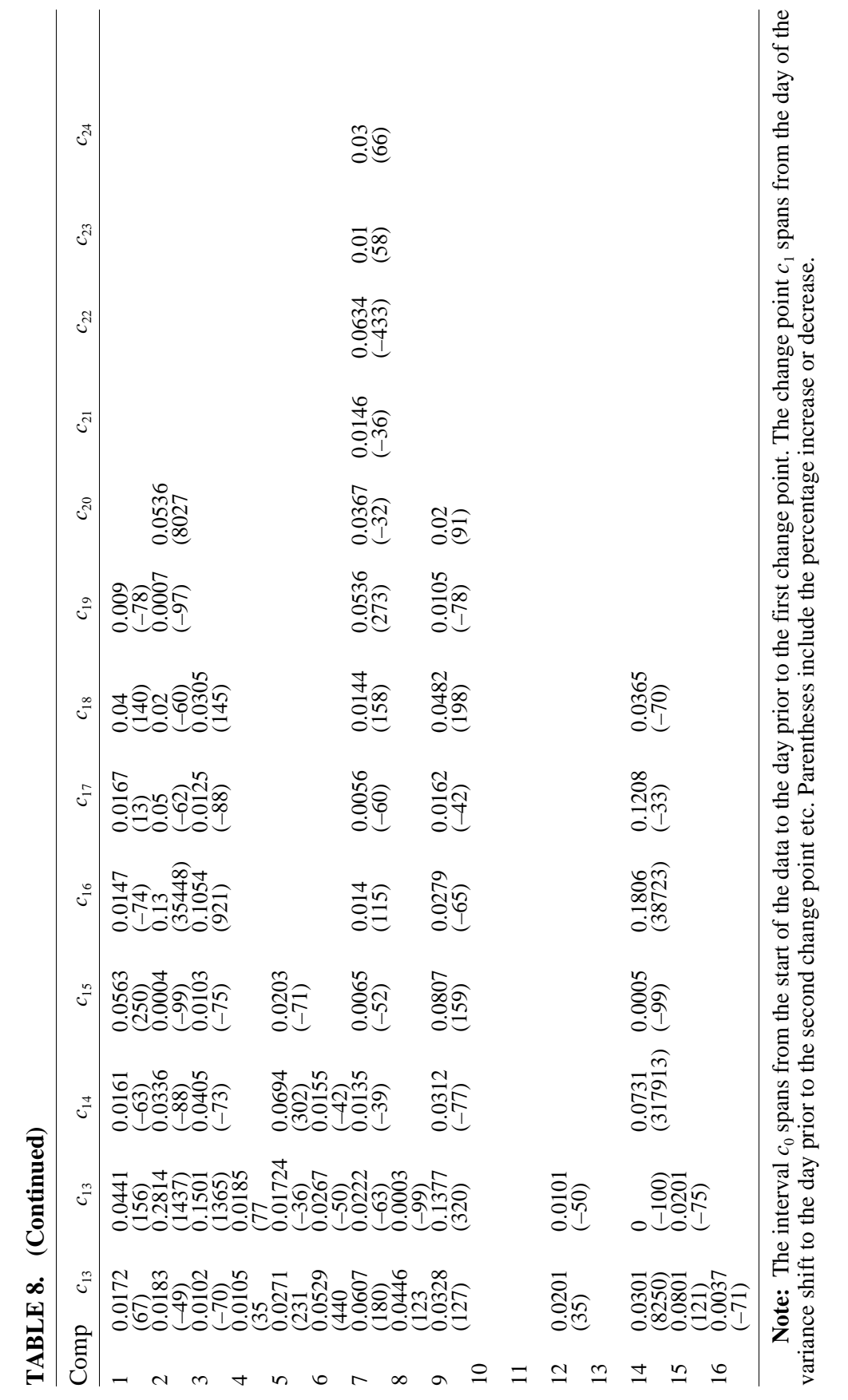




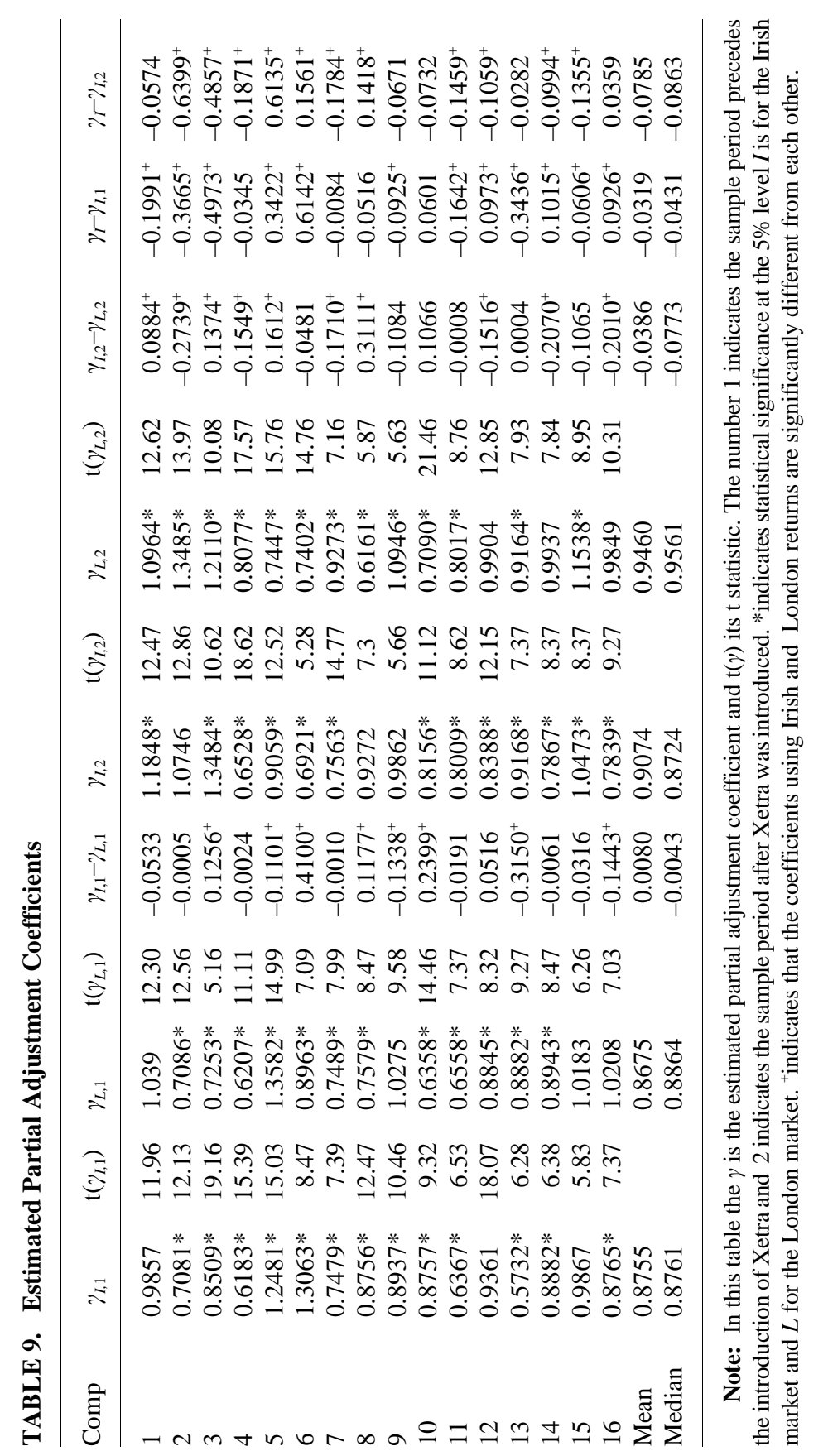




\section{Measuring the Speed of Adjustment}

To examine the volatility changes further we estimate the partial adjustment model of Amihud and Mendelson using a Kalman filter. ${ }^{9}$ This allows us to consider the contribution that changes to the speed of price discovery may have had on unconditional volatility.

We can re-write the partial adjustment model, of equation 1 , as follows

$$
R_{t}=g V_{t}-g P_{t-1}+u_{t}
$$

where $R_{t}$ is the observed stock return on day $t$, and all other variables are as previously defined. If we now re-define $g V_{t}$ as at, we can write equation 1 and 2 in state space form to provide the measurement and the transition equation as shown in equation 9 and 10.

$$
R_{t}=a_{t}+\gamma P_{t-1}+u_{t}
$$

where $a_{t}$ is a time varying unobservable state variable. The $u_{t}$ reflects the influence of noise on current returns and has a variance $\sigma^{2}$. Since $V_{t}$ is a random walk with drift, the transition equation which describes the unobservable state variable at through time can be written as:

$$
\begin{gathered}
a_{t}=a_{t-1}+d+n_{t} \\
\text { for } n \sim\left(0, \sigma_{N}^{2}\right),
\end{gathered}
$$

where $a_{t}$ is $g V_{t}$ and is a random walk with drift, $d$ is the positive drift $g$ $\times m$ and $n_{t}$ is $g e_{t}$ which is a random variable with zero mean and finite variance. Thus, the values of $V_{t}$ through time can be obtained by taking $a_{t}$ and dividing by $\gamma$, the estimate of the partial adjustment coefficient.

Within the flexible framework used in this study the partial adjustment parameter of each market is able to adjust to changes in the intrinsic process that originate in either the home market or London. This allows us to determine whether the introduction of Xetra influenced the speed of adjustment in either market. We estimate this model using the security returns from the pre and post Xetra sub-samples. The results are contained in table 9.

9. Inclan and Tiao (1994) suggest within two data points. 


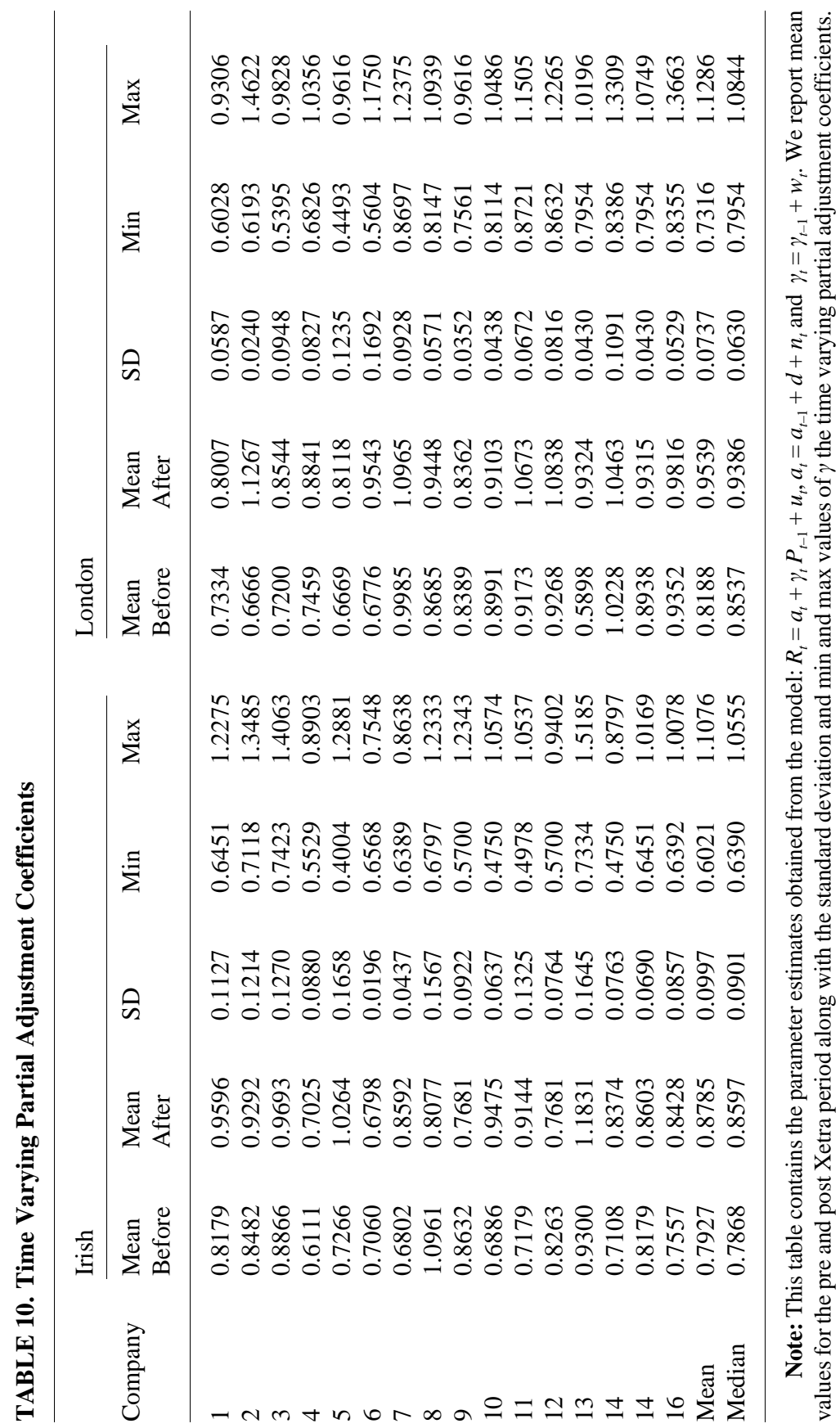


During the pre-Xetra period there is tendency for Dublin returns to under-adjust. The mean partial adjustment coefficient across all stocks is 0.8755 . Fourteen of these coefficients are less than unity (eleven of these are significant). Two securities are characterized by over-reaction as their partial adjustment coefficients are greater than one. London returns are also characterized by notable under-reaction. The mean London partial adjustment coefficient is 0.8675 . Eleven of these coefficients are less than one and significant.

During the second sub-period there is an increase in the adjustment coefficients in both markets. During the second period Dublin securities still tend to under-adjust as twelve of the securities display coefficients below one (nine of these are significant). However, the mean partial adjustment coefficient rises to 0.9074 and ten securities display partial adjustment coefficients that are higher during the post-Xetra period (seven are significantly higher). A similar pattern emerges in London. During the post-Xetra period, the partial adjustment coefficient rises for twelve securities. The mean partial adjustment coefficient rises to 0.9460 and four securities over-react.

The partial adjustment coefficients suggest that the introduction of Xetra did influence stock return volatility even though it could not be consistently detected in measures of variance. One explanation for this is that noise caused by the trading mechanism may have declined after the introduction of Xetra. Such changes would cause an offsetting reduction in return volatility. ${ }^{10}$

We next consider the impact that time varying parameter estimates might have on our findings. Changing volatility has been shown to play an important role in influencing the adjustment speed of prices. Ross (1989) argues that volatility can be viewed as a measure of information flow because the variance of price changes is directly related to the flow of new information. Therefore, volatility increases arise when investors utilize new information that moves prices. Kim and Verrechia (1991a), (1991b) and (1997) have also shown that the amount of volatility is related to the quality of the new information that arrives. The better the quality of information and the less pre-announcement leakage that has taken place the greater the price impact and the more volatile returns become.

In an attempt to capture the dynamics of the partial adjustment process, we estimate a second model in which the partial adjustment parameter is assumed to follow a random walk. The measurement

10. It is also possible that the variance of the intrinsic process may have changed. 
equation now has a time varying partial adjustment parameter $\gamma_{t}$. The transition equation has two components, equation 11 describes the evolution of at while equation 12 describes the evolution of $\gamma_{t}$ as a random walk.

$$
\begin{gathered}
R_{t}=a_{t}+\gamma_{t} P_{t-1}+u_{t} \\
a_{t}=a_{t-1}+d+n_{t} \\
\gamma_{t}=\gamma_{t-1}+w_{t}
\end{gathered}
$$

where $\gamma_{t}$ is the time varying partial adjustment process and $w_{t}$ is a white noise series of errors, which are independent of $u_{t}$ and $n_{t} . E\left(w_{t}\right)=0$ and the variance of $w_{t}$ is $w^{2}$. The other terms are as previously defined.

For each security this model is estimated using the full sample of returns. From the time varying parameters we calculate the mean value of the partial adjustment coefficient prior and subsequent to the introduction of Xetra. The results are contained in table 10. The mean partial adjustment coefficient estimated for the pre and post Xetra periods indicate that there is a tendency for the time varying adjustment coefficient to rise in the post Xetra period. The average partial adjustment coefficient across all Irish listed securities is 0.7927 prior to Xetra being introduced and rises to 0.8785 post-Xetra. A similar pattern emerges for London securities. Pre-Xetra the mean partial adjustment coefficient across all securities is 0.8188 and rises to 0.9539 in the post Xetra period. The results show that the rise in the speed of price discovery is most pronounced for London listed securities confirming our earlier results. This suggests that the greater operational efficiency offered by Dublin as a consequence of Xetra may have enhanced operational efficiency in London. We conclude that the introduction of Xetra exerted an important influence upon price discovery in both the home and London market.

\section{Summary and Conclusions}

Motivated by the introduction of Xetra in the Dublin market this paper formally studies the market microstructure of the Irish stock market. This is the first time the Dublin market has been examined in depth. Because the trading mechanism can exert a strong influence over the volatility of stock returns in the first instance we examine whether 
security volatility changed in the post-Xetra period. Using a range of tests we find that no clear cut pattern emerges to suggest that volatility increased or decreased after the new trading system was introduced.

A weakness of examining volatility across two sub-periods is that it presupposes volatility unrelated to the trading system remains constant. To counteract this unrealistic assumption we apply the ICSS algorithm of Inclan and Tiao (1994) that identifies all variance changes associated with a data series. The algorithm allows us to discover whether there is a wide-scale shift in volatility at the time Xetra was introduced. The results suggest only a few securities display evidence of a variance shift at the time Xetra was introduced.

As demonstrated by Amihud and Mendelson (1987) the volatility of stock returns is determined by the complex interrelationship of a number of factors. We therefore extend our analysis to examine whether the introduction of Xetra influenced the speed of price discovery in either Dublin or London. We find that in the post Xetra period both Dublin and London prices adjust faster to the arrival of new information.

\section{Appendix 1: Names of Companies in the Sample}

1. Abbey

2. Arcon

3. Barlo

4. DCC

5. Dragon Oil

6. Fyffes

7. Kenmare

8. Norish
9. Glanbia

10. Greencor

11. Heiton

12. Irish Co

13. Kingspan

14. Qualceram Shires

15. Unidare

16. United Drug

\section{References}

Aggarwal, R.; Inclan, C.; and Leal, R. 1999. Volatility in emerging markets. Journal of Financial and Quantitative Analysis 16: 356-368.

Amihud, Y. and Mendelson, H. 1980. Dealership market: Market-making with inventory. Journal of Financial Economics 8: 31-53.

Amihud, Y. and Mendelson, H. 1982. Asset price behavior in a dealership market. Financial Analysts Journal 38: 50-59.

Amihud, Y. and Mendelson, H. 1987. Trading mechanisms and stock returns: An empirical investigation. Journal of Finance 62: 533-553.

Benveniste, L.M.; Marcus A.; and Wilhelm, W. 1992. What's special about the specialist? Journal of Financial Economics 32: 61-86.

Biais, B. 1993. Price formation and equilibrium liquidity in fragmented and 
centralized markets. Journal of Finance 68: 157-185.

Black, F. 1976. Studies in stock price volatility changes. Proceedings of the 1976 Business Meeting of the Business and Economics Statistics, Section American Statistical Association, 177-181.

Black, F. 1986. Noise. Journal of Finance 41: 529-543.

Bollerslev, T.; Chou, R. Y.; and Kroner, K. F. 1992. ARCH modeling in finance: A review of the theory and empirical evidence. Journal of Econometrics 52: 5-59.

Board, J. and Sutcliffe, C. 1995. The effects of trade transparency in the London Stock Exchange. London International Financial Futures and Options Exchange and London Stock Exchange.

Board, J. and Sutcliffe, C. 2000. The Proof of the Pudding: The effects of increased trade transparency in the London Stock Exchange. Journal of Business Finance and Accounting 27: 887-909.

Bollerslev, T. 1986. Generalized autoregressive conditional heteroscedasticity. Journal of Econometrics 31:307-327.

Chelley-Steeley, P.L. 2005. Noise and the trading system: The case of SETS. European Financial Management 3: 389-425.

Christie, A. 1982. The stochastic behavior of common stock variances: Valueleverage and interest rates. Journal of Financial economics 10: 407-432.

Conrad, J.; Kaul G.; and Nimalendran, M. 1991. Asymmetric predictability of conditional variances. Review of Financial Studies 4: 597-622.

Cohen, K.; Maier, S.; Schwartz, R.; and Whitcomb, D. 1978. The return generation process, returns variance and the effect of thinness in securities markets. Journal of Finance 33: 149-167.

de Jong, F.; Nijman, T.; and Roell, A. 1995. A comparison of the cost of trading French shares on the Paris Bourse and on SEAQ international. European Economic Review 39: 1277-1301.

de Jong, F.; Nijman, T.; and Roell, A. 1996. Price effects of trading components of the bid-ask spread on the Paris Bourse. Journal of Empirical Finance 3: 193-213.

Domowitz, I. and Steil, B. 1999. Automation, trading costs and the structure of the trading services industry. Brookings-Wharton papers on financial services.

Gemmill 2001. Letter, London Evening News.

Engle, R.F. and Ng, V. 1993. Measuring and testing the impact of news on volatility. Journal of Finance 48: 1749-1778.

Fama E. 1965. The behavior of stock market prices. Journal of Business 38: 34-105.

French, K. and Roll, R. 1986. Stock return variances: The arrival of information and the reaction of traders. Journal of Financial Economics 17: 5-26.

Glosten, L.; Jagannathan, R.; and Runkle, D. 1993. On the relation between the expected value and the volatility of the nominal excess return on stocks. Journal of Finance 48: 1779-1801. 
Handa, P. and Schwartz, R.A. 1996. Limit order trading. Journal of Finance 51: $1835-1861$.

Harvey, A. 1989. Forecasting, Structural Time Series Models and the Kalman Filter. Cambridge University Press.

Huang, R. and Stoll, H. 1996. Dealer versus auction markets: A paired comparison of execution costs on Nasdaq and NYSE. Journal of Financial Economics 41: 313-357.

Inclan, C. and Tiao, G. 1994. Use of cumulative sums of squares for retrospective detection of changes of variance. Journal of the American Statistical Association 89: 913-923.

Kim, O. and Verrecchia, R. 1991a. Market reaction to anticipated announcements. Journal of Financial Economics 29: 273-309.

Kim, O. and Verrecchia, R. 1991b. Trading volume and price reactions to public announcements. Journal of Accounting Research 29: 302-321.

Kim, O. and Verrecchia, R. 1997. Pre-announcement and event-period private information. Journal of Accounting and Economics 24: 395-419.

Liu, Y.A. and Pan, M-S. 1997. Mean and volatility interdependencies in US and Asia-Pacific Basin Stock Markets. Multinational Finance Journal 1: 47-62.

Madhavan, A. 1992. Trading mechanisms in securities markets. Journal of Finance 47: 607-641.

Mandelbrot, B. 1963. The variation of certain speculative prices. Journal of Business 36: 394-419.

Ozenbas, D.; Schwartz R.; and Wood, R.A. 2002. Volatility in US and European equity markets: An assessment of market quality. International Finance 5: 1-25.

Pagano, M. 1998. The changing microstricture of European equity markets. In the European Securities Markets: The Investment Services Directive and Beyond. Kluwer Law International.

Pagano, M.S. and Schwartz, R.A. 2003. A closing call's impact on market quality at Euronext Paris. Journal of Financial Economics 68: 439-484.

Pagano, M. and Steil, B. 1995. The Evolution of European Trading Systems in the European Equity Markets. The Royal Institute of International Affairs.

Ronen, T. 1998. Trading structure and overnight information: A natural experiment from the Tel-Aviv stock exchange. Journal of Banking and Finance 22: 489-512.

Ross, S.A. 1989. Information and Volatility: The no arbitrage martingale approach to timing and resolution irrelevancy. Journal of Finance 44: 1-17.

Stoll, H. and Whaley, R. 1990. Stock market structure and volatility. Review of Financial Studies 3: 37-71.

Theissen, E. 2000. Market structure, informational efficiency and liquidity: An experimental comparison of auction and dealer markets. Journal of Financial Markets 3:333-363.

Venkataraman, K. 2001. Automated versus floor trading: An analysis of execution costs on the Paris and New York Exchanges. The Journal of Finance 56: 1445-1485. 